\title{
Off-pump coronary artery bypass grafting provides complete revascularization with reduced myocardial injury, transfusion requirements, and length of stay: A prospective randomized comparison of two hundred unselected patients undergoing off-pump versus conventional coronary artery bypass grafting
}

J. D. Puskas, MD, ${ }^{a}$ W. H. Williams, MD, ${ }^{a, d}$ P. G. Duke, MD, ${ }^{c}$ J. R. Staples, MD, ${ }^{c}$ K. E. Glas, MD, ${ }^{c}$ J. J. Marshall, MD, ${ }^{b}$ M. Leimbach, MD, ${ }^{\text {b }}$ P. Huber, MD, ${ }^{\text {b }}$ S. Garas, MD, ${ }^{\text {b }}$ B. H. Sammons, RN, ${ }^{a}$ S. A. McCall, RN, ${ }^{a}$ R. J. Petersen, RN, $^{a}$

D. E. Bailey, RN, PA-C, ${ }^{a}$ H. Chu, PhD, ${ }^{d}$ E. M. Mahoney, PhD, ${ }^{d}$ W. S. Weintraub, MD, ${ }^{d}$ and R. A. Guyton, MD ${ }^{a}$

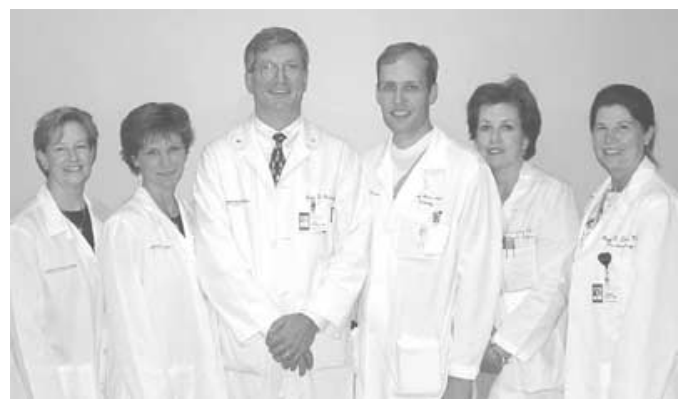

From the Divisions of Cardiothoracic Surgery, ${ }^{\mathrm{a}}$ Cardiology, ${ }^{\mathrm{b}}$ and Cardiac Anesthesiology, ${ }^{\mathrm{c}}$ Emory University School of Medicine, and the Emory Center for Outcomes Research, ${ }^{\mathrm{d}}$ Atlanta, Ga.

Supported by grants from Medtronic, Inc, Minneapolis, Minn, and The Carlyle Fraser Heart Center Foundation, Atlanta, Ga.

Read at the Eighty-second Annual Meeting of The American Association for Thoracic Surgery, Washington, DC, May 5-8, 2002.

Received for publication May 5, 2002; revisions requested June 14, 2002; revisions received June 27, 2002; accepted for publication July 8, 2002.

Address for reprints: John D. Puskas, MD, MSc, FACS, Associate Professor of Surgery (Cardiothoracic), Emory University School of Medicine, Crawford Long Hospital, Sixth Floor, Medical Office Tower, 550 Peachtree St, NE, Atlanta, GA 30308 (Email: john_puskas@emoryhealthcare.org).

J Thorac Cardiovasc Surg 2003;125: 797-808

Copyright $\odot 2003$ by The American Association for Thoracic Surgery

$0022-5223 / 2003 \$ 30.00+0$

doi: $10.1067 / \mathrm{mtc} .2003 .324$
Objective: Retrospective comparisons of selected patients undergoing off-pump versus conventional on-pump coronary artery bypass grafting have yielded inconsistent results and raised concerns about completeness of revascularization in off-pump coronary artery bypass grafting.

Methods: Two hundred unselected patients referred for elective primary coronary artery bypass grafting were randomly assigned to undergo off-pump coronary artery bypass grafting with an Octopus tissue stabilizer (Medtronic, Inc, Minneapolis, Minn) or conventional coronary artery bypass grafting with cardiopulmonary bypass by a single surgeon. Revascularization intent determined before random assignment was compared with the revascularization performed. All management followed strict, unbiased, criteria-driven protocols. Patients and nonoperative care providers were blinded to surgical group.

Results: Baseline characteristics were similar. The number of grafts performed per patient (mean \pm SD $3.39 \pm 1.04$ for off-pump coronary artery bypass grafting, $3.40 \pm 1.08$ for conventional coronary artery bypass grafting) and the index of completeness of revascularization (number of grafts performed/number of grafts intended, $1.00 \pm 0.18$ for off-pump coronary artery bypass grafting, $1.01 \pm 0.09$ for conventional coronary artery bypass grafting) were similar. Likewise, the index of completeness of revascularization was similar between groups for the lateral wall. Combined hospital and 30-day mortalities and stroke rates were similar. Postoperative myocardial serum enzyme measures were significantly lower after off-pump coronary artery bypass grafting, suggesting less myocardial injury. Adjusted postoperative thromboelastogram indices, fibrinogen, international normalized ratio, and platelet levels all showed significantly less coagulopathy after off-pump coronary 
artery bypass grafting. Patients undergoing off-pump coronary artery bypass grafting received fewer units of blood, were more likely to avoid transfusion altogether, and had a higher hematocrit at discharge. Cardiopulmonary bypass was an independent predictor of transfusion (odds ratio 2.42, $P=.0073$ ) by multivariate analysis. More patients undergoing off-pump coronary artery bypass grafting were extubated in the operating room and within 4 hours. Postoperative length of stay (in days) was shorter for off-pump coronary artery bypass grafting $(5.1 \pm 6.5$ for off-pump coronary artery bypass grafting, $6.1 \pm 8.2$ for conventional coronary artery bypass grafting, $P=.005$ by Wilcoxon test). One patient (in the conventional coronary artery bypass grafting group) required angioplasty for graft closure within 30 days.

Conclusions: When compared with conventional coronary artery bypass grafting with cardiopulmonary bypass, off-pump coronary artery bypass grafting achieved similar completeness of revascularization, similar in-hospital and 30-day outcomes, shorter length of stay, reduced transfusion requirement, and less myocardial injury.

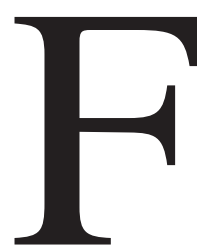

or more than 3 decades, surgical coronary revascularization has been accomplished with the use of cardiopulmonary bypass (CPB) in the vast majority of cases. However, offpump coronary artery bypass grafting (OP$\mathrm{CAB}$ ) has enjoyed a recent resurgence in interest and popularity, first in South America ${ }^{1,2}$ and then worldwide. ${ }^{3,4}$ This has been fueled by a growing awareness of the morbidity attributable to $\mathrm{CPB}$ and by refinement of instrumentation to facilitate beating heart surgery.

The diffuse inflammatory response elicited by CPB has been invoked to explain the small but finite incidence of serious injury in multiple organ systems, causing numerous postoperative complications and prolonging hospital length of stay. CPB, aortic crossclamping, and cardioplegia entail global myocardial ischemia during the crossclamp interval. Although effective cardioplegia reduces this risk, myocardial injury may still occur. This is manifested by release of myocardial enzymes and a small but finite incidence of Q-wave myocardial infarction. Hemodilution and hemolysis are direct consequences of CPB and may produce significant coagulopathy, necessitating transfusion of blood products.

Although OPCAB now accounts for approximately $18 \%$ of coronary artery bypass grafting (CABG) procedures performed in the United States, as reported by the National Society of Thoracic Surgeons Adult Cardiac Database Fall 2001 report (data reported through June 2001, http://www. sts.org), concern has been raised about the difficulty of this rediscovered operation and the possibility that incomplete revascularization may compromise patient outcomes. ${ }^{5,6}$ Those retrospective comparisons favoring OPCAB over $\mathrm{CABG}$ with $\mathrm{CPB}^{7}$ have been appropriately criticized for bias inherent in patient selection for OPCAB and for "fasttrack" management selectively applied to patients undergoing OPCAB. Thus previous retrospective and nonrandomized comparisons of OPCAB versus $\mathrm{CABG}$ with $\mathrm{CPB}$ may have used inadequately matched control groups. Even retrospective studies applying sophisticated statistical analyses to very large databases ${ }^{8,9}$ and reporting significant benefits of OPCAB over CABG with CPB for mortality, stroke, and many other complications are subject to this criticism. Moreover, most previous studies have failed to adequately address legitimate concerns about the completeness of revascularization provided or to document the quality of anastomoses constructed during OPCAB by directly assessing graft patency. Indeed, all but a very few ${ }^{10}$ of the dozens of nonrandomized comparisons published since 1998 reported statistically fewer grafts performed in the OPCAB group. Of course, this does not necessarily indicate incomplete revascularization in the OPCAB group, because surgeons during the "learning curve" may have correctly and consciously excluded some patients from OPCAB on the basis of coronary anatomy. In particular, multiple grafts to the lateral wall may be challenging without considerable OPCAB experience. Nonetheless, this observed difference in number of grafts between groups does at least indicate an imperfect composition of the chosen "matched" control groups.

A prospective, randomized study ${ }^{11}$ among 80 selected patients heightened concerns about completeness of revascularization in OPCAB when it reported significantly fewer grafts in the OPCAB group than in the CABG with CPB group (2.6 \pm 0.5 vs $3.1 \pm 0.8, P=.04)$. Two other groups have published results of randomized comparisons of OPCAB versus $\mathrm{CABG}$ with $\mathrm{CPB}$ with substantial statistical power. Van Dijk and colleagues ${ }^{12}$ randomly assigned 281 
selected patients and reported equivalent completeness of revascularization but only $2.4 \pm 1.0$ grafts in the OPCAB group versus $2.6 \pm 1.1$ grafts in the $\mathrm{CABG}$ with $\mathrm{CPB}$ group $(P=.05)$. Fewer than $25 \%$ of patients enrolled in this study had three-vessel disease; $78 \%$ had normal left ventricular function. Ascione and associates ${ }^{13}$ randomly assigned 200 selected patients and performed $2.23 \pm 0.83$ grafts in the $\mathrm{OPCAB}$ group and $2.31 \pm 0.86$ grafts in the $\mathrm{CABG}$ with $\mathrm{CPB}$ group (difference not statistically significant). None of these patients required grafting of the distal circumflex territory, and $80 \%$ had left ventricular ejection fractions greater than $50 \%$. There have been no published reports comparing $\mathrm{OPCAB}$ versus $\mathrm{CABG}$ with $\mathrm{CPB}$ among randomly assigned patients unselected for coronary anatomy, ventricular function, or comorbidities.

\section{Methods}

\section{Patient Enrollment and Random Assignment}

The SMART Study (Surgical Management of Arterial Revascularization Therapies) was designed to rigorously compare completeness of revascularization, clinical outcomes, and resource use in unselected patients referred for elective, primary $\mathrm{CABG}$ randomly assigned to undergo OPCAB with an Octopus tissue stabilizer (Medtronic, Inc, Minneapolis, Minn) or CABG with CPB. In an effort to minimize variability, all procedures were performed by a single experienced surgeon (JDP), and all patient management was conducted by a single team according to strict, unbiased, blinded, criteria-driven protocols. A sincere effort was made to enroll patients representative of the general patient population referred for CABG in the United States in the years 2000 and 2001. Thus patients were not excluded on the basis of any preoperative comorbidity or any pattern of coronary artery disease. Only patients in cardiogenic shock and those requiring preoperative intraaortic balloon pump counterpulsation were excluded from the study for cardiac reasons. Patients who had chronic renal insufficiency with a creatinine level greater than $2.5 \mathrm{mg} / \mathrm{dL}$ were eligible for enrollment in the study but were exempt from having postoperative cardiac angiography performed. Patients who were hemodialysis dependent, however, were eligible for enrollment and were asked to participate in postoperative angiography. An attempt was made to randomly assign 1 patient each operative day. Each patient referred was screened and asked to volunteer. This process continued each day until 1 patient had agreed to participate in the study for the next operative day. This was done to facilitate accurate and complete data acquisition in the light of manpower limitations. Thus the 200 randomly assigned patients were not in fact consecutive referrals to this surgeon. After approval by the institutional review board of Emory University, Atlanta, Ga, the first patient was enrolled on March 20, 2000. The 200th patient completed enrollment on August 10, 2001. During this 17-month period, the operating surgeon performed primary, elective, isolated CABG for a total of 465 patients. Although $64 \%$ of all eligible patients were screened and either enrolled or refused participation, the other $36 \%$ of the population were not approached for various logistic reasons, such as a previous patient having already consented to participate the next day, unavailability of clinical research staff, weekend procedures, or surgical scheduling. Thus
$43 \%$ of the total eligible patients during this period were enrolled in the SMART Study. Three patients were found to require mitral valve repair or replacement after random assignment and were subsequently excluded from the study. One patient withdrew from the study immediately after surgery. His preoperative and acute hospital data were included in the analysis, but no long-term data were collected.

Patients were randomly assigned by means of a computergenerated random number table. This was done for each patient after the operating surgeon had documented the intended revascularization to be performed, which was based on review of the preoperative coronary arteriogram. Random assignment was stratified by sex and diabetic status to insure roughly equal numbers of patients within strata defined by these prognostically relevant characteristics. Random assignment was carried out separately within each stratum with randomly permuted blocks of size 4 and 6 to preserve approximate balance and prevent correct prediction of the next assignment by the clinical recruiting staff.

\section{Crossing Over Between Groups and Blinding to Group Assignment}

Patients were allowed to cross over between groups whenever the treating surgeon considered that this would be unequivocally in the patient's best interest. All patients, their families, referring cardiologists, and nonoperative care providers were blinded as to group assignment. This blinding will be maintained through the 1-year follow-up period.

\section{Patient Management Protocols}

Patients participating in the SMART Study were identified simply as "SMART Study patients," and their care was managed according to strict, unbiased, criteria-driven, printed protocols. There protocols were developed specifically to standardize management of study patients and were applied identically to both groups. Protocols controlled preoperative care, anesthesia and analgesia (before, during, and after the operation), extubation, intensive care unit management and transfer, ambulation, diet, medications, transfusion, all laboratory and radiologic examinations, and discharge planning. Each of these protocols was translated to patient order forms and placed on the chart of each patient enrolled. Thus, for instance, each study patient received identical anesthetic premedication and identical anesthesia in the operating room. A separate, defined protocol determined whether an individual patient was extubated in the operating room or in the intensive care unit. Each patient was required to meet specific criteria to be extubated, and each patient was extubated as soon as these criteria were met. Thus the opportunity for biased or selective "fasttracking" of patients undergoing OPCAB was minimized or eliminated.

\section{Data Acquisition and Management}

Preoperative data acquisition included a complete assessment of patient demographics, preoperative risk factors, and preoperative medications. Preoperative neurologic and quality of life assessments included administration of the National Institutes of Health Stroke Scale by a trained physician assistant and the Euroquol and SF-36 self-reporting questionnaires. Table 1 reports the timing of various investigations. 
TABLE 1. Timing of study interventions

\begin{tabular}{|c|c|c|c|c|c|c|c|c|}
\hline & Preoperative & $\begin{array}{l}\text { Operating } \\
\text { room }\end{array}$ & $\begin{array}{c}\text { Intensive } \\
\text { care }\end{array}$ & $\begin{array}{c}\text { Postoperative } \\
\text { d } 1\end{array}$ & $\begin{array}{c}\text { Discharge } \\
\text { (3-5 d) }\end{array}$ & $\begin{array}{c}\text { 6-wk } \\
\text { follow-up }\end{array}$ & $\begin{array}{c}\text { 6-mo } \\
\text { follow-up }\end{array}$ & $\begin{array}{c}\text { 12-mo } \\
\text { follow-up }\end{array}$ \\
\hline Coronary angiography & $\mathrm{X}$ & & & $\mathrm{x}$ & & & & $\mathrm{X}$ \\
\hline Complete history and physical examination & $\mathrm{x}$ & & & & & & & \\
\hline Physical assessment & & & & & $\mathrm{X}$ & $\mathrm{x}$ & & $\mathrm{X}$ \\
\hline Angina assessment & $\mathrm{X}$ & & & & & & & $\mathrm{X}$ \\
\hline Medication history & $\mathrm{x}$ & & & & & $\mathrm{x}$ & & $\mathrm{x}$ \\
\hline ECG & $\mathrm{X}$ & & $\mathrm{X}$ & & & & & $\mathrm{X}$ \\
\hline National Institutes of Health Stroke Scale & $\mathrm{x}$ & & & & $\mathrm{x}$ & $\mathrm{X}$ & & \\
\hline SF-36 and Euroqol & $\mathrm{x}$ & & & & & $\mathrm{x}$ & $\mathrm{x}$ & $\mathrm{x}$ \\
\hline Laboratory tests & $\mathrm{x}$ & $\mathrm{x}$ & $\mathrm{X}$ & $\mathrm{x}$ & $\mathrm{x}$ & & & $x$ \\
\hline Diffusion-weighted magnetic resonance imaging & & & & & $\mathrm{x}$ & & & \\
\hline Transesophageal echocardiogram & & $\mathrm{x}$ & & & & & & \\
\hline Chest radiograph & $\mathrm{X}$ & $\mathrm{X}$ & $\mathrm{X}$ & & $\mathrm{x}$ & $\mathrm{X}$ & & \\
\hline Pulmonary function test & $\mathrm{x}$ & & & & & $\mathrm{x}$ & & \\
\hline Resource use & $\mathrm{x}$ & & $\mathrm{x}$ & & & $\mathrm{x}$ & $\mathrm{x}$ & $\mathrm{x}$ \\
\hline
\end{tabular}

All data were gathered prospectively and recorded by one of two clinical research nurse coordinators assigned to the management of the study. Case report forms (CRFs) were designed and developed with a Teleform software package (TELEform Elite; Cardiff Software Ltd, Vista, Calif). Completed CRFs were logged on to the "CRF log form" and copied and transported to Emory Center for Outcomes Research (ECOR), where each CRF was again logged into the ECOR system by an assigned project data manager. The Teleform CRF was then electronically scanned and imported into a predesigned ACCESS relational database (Microsoft, Redmond, Wash). Data integrity and completeness were monitored and maintained through manual and electronic mechanisms. Copies of each CRF were stored within a locked and monitored office environment. All study data were therefore deposited and managed in an independent data warehouse, maintaining an arm's-length distance between the clinical team and the data repository. Serial 12-lead electrocardiograms (ECGs) were evaluated and scored for perioperative myocardial infarction according to the Minnesota Code at an external ECG core laboratory ( $\mathrm{St}$ Louis University Core ECG Lab, St Louis, Mo). These data were independently delivered to ECOR. All data analysis, data interpretation, and manuscript review were performed under the direction of a doctoral-level biostatistician at ECOR. The sponsors of this trial played no role in study design; in the collection, analysis, and interpretation of data; or in the writing of this report.

\section{Power Calculations and Statistical Analysis}

The sample size was chosen for the ability to detect a difference of $5 \%$ between treatment groups in the primary end point, graft patency. Assuming a conservative estimate of an average of 3 grafts performed per patient, and making the further assumption that patency outcomes of grafts within a patient are independent, 100 patients in each treatment arm would yield $78 \%$ power to detect a difference in patency rate of 5\%, assuming a type 1 error rate of .05 . Eighty percent power would be achieved with an average of 3.08 grafts per patient. Although an overall higher number of grafts per patient was anticipated, the nonindependence of patency outcomes within patients, which are taken into account in the analysis, would effectively lower the power to a small extent. Overall, 100 patients in each treatment group should conservatively yield $80 \%$ power to detect the $5 \%$ difference in patency rates that is considered clinically important.

The index of completeness of revascularization (ICOR, number of grafts performed/number of grafts intended) was compared between treatment arms with the Wilcoxon rank sum test. Dichotomous morbidity and mortality outcomes were analyzed with the Fisher exact test. All data analysis was according to intent to treat. All 4 patients who crossed over between groups were also analyzed according to intent to treat. Analysis of covariance was used to compare postoperative laboratory values between treatment groups after adjustment for preoperative levels. Discrete data are presented as percentages; continuous data are presented as mean \pm SD.

\section{Follow-up}

All 192 eligible patients completed personal or telephone interviews approximately 30 days after surgery. These interviews assessed adverse events, complications, readmissions, and reinterventions.

\section{Surgical Technique}

General. Surgical access to the heart was through a standard median sternotomy in all cases. All incisions and closure techniques were the same for both groups, limiting variability and maintaining blinding of group assignment for patients, families, and referring cardiologists. A cell saver reservoir (COBE Cardiovascular, Inc, Arvada, Colo) was set up for all patients in both groups. Blood was spun down and returned to all patients when the quantity was sufficient. All patients had epiaortic ultrasonography performed immediately after pericardiotomy. Patients discovered to have a heavily calcified or severely atheromatous ascending aorta (grade $\geq 3$ ) that precluded safe cannulation or crossclamping were treated with an aortic "no-touch" technique. This required that such patients randomly assigned to OPCAB had internal thoracic arteries used for sole 
coronary inflow and those randomly assigned to CABG with $\mathrm{CPB}$ were converted to the OPCAB group. Patients randomly assigned to the off-pump technique for whom complete revascularization was not technically feasible without the use of CPB were allowed to cross over to the on-pump group. Thus enrollment in this study did not compromise the standard of care provided to any patient. Fine monofilament suture (8-0 Surgipro; United States Surgical Corporation, Norwalk, Conn) was used for all distal anastomoses, with the exception of heavily calcified, largecaliber coronaries that could not be penetrated with an 8-0 needle. A humidified carbon dioxide blower (Medtronic DLP, Minneapolis, Minn) was used to disperse blood from the anastomotic site during construction of distal anastomoses in both groups. Proximal anastomoses were performed with 5-0 or 6-0 Surgipro suture for venous anastomoses and 6-0 or 7-0 Surgipro suture for arterial anastomoses to the aorta.

OPCAB technique. OPCAB was performed with the Medtronic Octopus II (March 2000-May 2000) and Octopus III (May 2000-August 2001) stabilizing devices for coronary stabilization and deep pericardial traction sutures for cardiac displacement and presentation. This was accomplished according to techniques previously described elsewhere, with great care taken to maintain hemodynamic stability (mean arterial blood pressures $\geq 65 \mathrm{~mm} \mathrm{Hg}$ ) throughout the operation. ${ }^{14}$ Perfusion-assisted direct coronary artery bypass with the Quest Medical myocardial protection system (Quest Medical, Dallas, Tex) was used at the discretion of the surgeon in 1 patient in the OPCAB group with critical left main coronary artery stenosis and profoundly depressed left ventricular ejection fraction. ${ }^{15}$

CABG with CPB technique. Conventional $\mathrm{CABG}$ with $\mathrm{CPB}$ was accomplished with every effort made to minimize the impact of CPB. Patients without diabetes received 250 mg methylprednisolone sodium succinate (Solu-Medrol) intravenously before induction of anesthesia in the CABG with CPB group only. Cannulation and single aortic clamping were guided by the results of individual epiaortic ultrasonographic scanning of the ascending aorta. The SARNS "soft-flow" aortic cannula, a two-stage venous cannula, and retrograde blood cardioplegia catheter were used for all patients in the CABG with CPB group (3M Health Care, Ann Arbor, Mich). A phrenic nerve pad was used to thermally insulate the heart and to protect the phrenic nerve. The patients were routinely cooled to $34^{\circ} \mathrm{C}$ for operations when 3 or fewer grafts were anticipated. When 4 or more grafts were anticipated, the patient was cooled to $32^{\circ} \mathrm{C}$. The COBE disposable arterial-venous circuit was used with a $40-\mu \mathrm{m}$ arterial line filter and 0.5 -inch thick-walled pump head boot. The COBE CML Duo oxygenator and the COBE heart-lung machine were used. Hemoconcentration was used for patients in congestive heart failure or renal failure and for those whose venous reservoir accumulated more than $2 \mathrm{~L}$ of volume. The Quest Medical Myocardial Protection System was used to deliver cold $\left(5^{\circ} \mathrm{C}-8^{\circ} \mathrm{C}\right)$, intermittent, high-potassium antegrade and retrograde 4:1 blood cardioplegia in all on-pump cases.

\section{Results}

Three patients were found by intraoperative transesophageal echocardiography to require mitral valve repair or replacement after random assignment and were subsequently excluded from the study. Thus data analysis was based on 98 patients in the OPCAB group and 99 patients in the $\mathrm{CPB}$ group. Baseline characteristics were similar between the groups (Table 2). Three patients randomly assigned to conventional $\mathrm{CABG}$ with $\mathrm{CPB}$ in whom epiaortic ultrasonography demonstrated heavy calcification or severe atherosclerosis of the ascending aorta were crossed over to the OPCAB limb and treated with an aortic "no-touch" technique with internal thoracic artery conduits for coronary inflow. Conversely, 1 patient randomly assigned to the OPCAB group had a tear occur in the right ventricle during left internal thoracic artery anastomosis to a deep intramyocardial left anterior descending coronary artery, and the procedure was intraoperatively converted to $\mathrm{CPB}$ at the surgeon's discretion.

Table 3 reveals that complications either in hospital or within 30 days of the operation were similar between groups. There were 3 deaths either in the hospital or within 30 days of surgery in the OPCAB group and 2 deaths in the CABG with CPB group. All 3 patients in the OPCAB group who died were extubated on the day of surgery, had cardiac catheterization on postoperative day 1 demonstrating that all grafts were patent, and variously died later of fulminant pseudomembranous colitis on postoperative day 32, heparin-induced thrombocytopenia on postoperative day 44 , and a primary arrhythmia on postoperative day 3 . The patient with the primary arrhythmia also underwent autopsy, which demonstrated that all grafts were still patent. Neither of the 2 patients in the CABG with CPB group who died recovered from surgery to undergo postoperative catheterization. One died on postoperative day 7 of a massive perioperative cerebral infarction, whereas the other required reexploration for bleeding and later acquired adult respiratory distress syndrome and multisystem organ failure, dying on postoperative day 18. Neither had an autopsy performed. One patient in the OPCAB group and 2 patients in the CABG with $\mathrm{CPB}$ group had perioperative strokes. All perioperative strokes were confirmed by computed tomographic scanning and by a neurologist's examination. There was no significant difference in the incidence of postoperative atrial fibrillation between groups $(\mathrm{n}=16 / 98$ for OPCAB vs $\mathrm{n}=$ 22/99 for CABG with CPB, $P=.367$ ).

The number of grafts performed per patient $(3.39 \pm 1.04$ for $\mathrm{OPCAB}$ vs $3.40 \pm 1.08$ for $\mathrm{CABG}$ with $\mathrm{CPB}$ ) and the 
TABLE 2. Patient characteristics

\begin{tabular}{|c|c|c|c|}
\hline \multirow[b]{2}{*}{ Variables } & \multicolumn{3}{|c|}{ CABG with CPB } \\
\hline & OPCAB (n = 98) & (n = 99) & $P$ value \\
\hline Age $(y$, mean $\pm S D)$ & $62.2 \pm 11.1$ & $62.5 \pm 9.45$ & .973 \\
\hline Gender (No. female) & $22(22 \%)$ & $23(23 \%)$ & $>.999$ \\
\hline $\mathrm{BMI}\left(\mathrm{kg} / \mathrm{m}^{2}\right.$, mean $\left.\pm \mathrm{SD}\right)$ & $29.4 \pm 6$ & $28.1 \pm 4.5$ & .104 \\
\hline Baseline EF & & & .696 \\
\hline$>55 \%$ & $46(52 \%)$ & $47(52 \%)$ & - \\
\hline $45 \%-54 \%$ & $19(22 \%)$ & $20(22 \%)$ & - \\
\hline $35 \%-44 \%$ & $14(16 \%)$ & $11(12 \%)$ & - \\
\hline $25 \%-34 \%$ & $5(6 \%)$ & $7(5 \%)$ & - \\
\hline$<25 \%$ & $4(5 \%)$ & $6(7 \%)$ & - \\
\hline Previous MI & $34(35 \%)$ & $31(31 \%)$ & .649 \\
\hline $0-7 d$ & $13(14 \%)$ & $9(9 \%)$ & - \\
\hline$>7 \mathrm{~d}$ & $1(1 \%)$ & $2(2 \%)$ & - \\
\hline$>21 d$ & $12(13 \%)$ & $15(15 \%)$ & - \\
\hline Previous CVA & $1(1 \%)$ & $9(9 \%)$ & .018 \\
\hline Previous TIA & $3(3 \%)$ & $1(1 \%)$ & .621 \\
\hline COPD & $10(10 \%)$ & $8(8 \%)$ & .630 \\
\hline Current smoker & $27(28 \%)$ & $31(31 \%)$ & .640 \\
\hline Diabetes & $32(33 \%)$ & $33(30 \%)$ & $>.999$ \\
\hline Insulin & $9(29 \%)$ & $10(13 \%)$ & $>.999$ \\
\hline Oral agent & $22(12 \%)$ & $24(30 \%)$ & .863 \\
\hline Hypertension & $64(65 \%)$ & $61(62 \%)$ & .650 \\
\hline Previous angioplasty & $23(23 \%)$ & $15(15 \%)$ & .206 \\
\hline Prior stent & $9(9 \%)$ & $6(6 \%)$ & .430 \\
\hline Hypercholesterolemia & $48(49 \%)$ & $47(48 \%)$ & $>.999$ \\
\hline $\begin{array}{l}\text { Previous peripheral } \\
\text { vascular surgery }\end{array}$ & $13(14 \%)$ & $10(11 \%)$ & .657 \\
\hline Renal failure & 41 & $2(2 \%)$ & .682 \\
\hline Dialysis dependence & $1(1 \%)$ & $1(1 \%)$ & $>.999$ \\
\hline $\begin{array}{l}\text { NYHA functional class III } \\
\text { or IV }\end{array}$ & $2(2 \%)$ & $1(1 \%)$ & .620 \\
\hline CCS class III or IV & $24(25 \%)$ & $12(12 \%)$ & .027 \\
\hline $\begin{array}{l}\text { Preoperative } \\
\text { medications }\end{array}$ & & & \\
\hline Aspirin & $53(54 \%)$ & $57(58 \%)$ & .668 \\
\hline ACE inhibitors & $41(42 \%)$ & $37(37 \%)$ & .562 \\
\hline$\beta$-Blocker & $41(42 \%)$ & $48(48 \%)$ & .391 \\
\hline $\begin{array}{l}\text { Calcium-channel } \\
\text { blocker }\end{array}$ & $24(24 \%)$ & $22(22 \%)$ & .739 \\
\hline Diuretic & $16(16 \%)$ & $11(11 \%)$ & .308 \\
\hline Statin & $40(41 \%)$ & $33(33 \%)$ & .304 \\
\hline
\end{tabular}

All data are numbers of patients (with percentages) unless otherwise stated. $B M I$, Body mass index; $E F$, ejection fraction; $M I$, myocardial infarction; CVA, cerebrovascular accident; $T I A$, transient ischemic attack; COPD, chronic obstructive pulmonary disease; NYHA, New York Heart Association; CCS, Canadian Cardiovascular Society; ACE, angiotensin-converting enzyme.

ICOR $(1.00 \pm 0.18$ for OPCAB vs $1.01 \pm 0.09$ for $\mathrm{CABG}$ with $\mathrm{CPB}$ ) were similar between groups. Likewise, ICOR was similar between groups for the lateral wall $(1.00 \pm 0.18$ for OPCAB vs $1.01 \pm 0.09$ for $\mathrm{CABG}$ with $\mathrm{CPB}$ ). Thus in this study of 197 randomly assigned patients unselected for coronary anatomy, completeness of revascularization (as assessed by ICOR) was statistically similar between the OPCAB and CABG with CPB groups (Table 4). Moreover, arterial conduits constituted a similar proportion of grafts in
TABLE 3. Complications in hospital or within 30 days

\begin{tabular}{|c|c|c|c|c|c|}
\hline \multirow[b]{3}{*}{ Variable } & \multicolumn{5}{|c|}{ CABG with } \\
\hline & \multicolumn{2}{|c|}{$\begin{array}{l}\text { OPCAB } \\
(\mathrm{n}=98)\end{array}$} & \multicolumn{2}{|c|}{$\begin{array}{c}\text { CPB } \\
(n=99)\end{array}$} & \multirow[b]{2}{*}{$P$ value } \\
\hline & No. & $\%$ & No. & $\%$ & \\
\hline Operative mortality & 1 & 1 & 2 & 2 & $>.999$ \\
\hline In operating room & 0 & 0 & 0 & 0 & \\
\hline In hospital $<30 \mathrm{~d}$ & 1 & 1 & 2 & 2 & $>.999$ \\
\hline In hospital $>30 \mathrm{~d}$ & 2 & 2 & 0 & 0 & .246 \\
\hline Out of hospital $<30 \mathrm{~d}$ & 0 & 0 & 0 & 0 & \\
\hline \multicolumn{6}{|l|}{ Cardiac } \\
\hline Reoperation for bleeding & 1 & 1 & 2 & 2 & $>.999$ \\
\hline Reoperation for graft occlusion & 0 & 0 & 0 & 0 & $>.999$ \\
\hline Angioplasty & 0 & 0 & 1 & 1 & \\
\hline Stent & 0 & & 1 & 1 & $>.999$ \\
\hline $\begin{array}{l}\text { Myocardial infarction, new } 0 \\
\text { wave }\end{array}$ & 1 & 1 & 2 & 2 & $>.999$ \\
\hline Angina & 0 & & 1 & 1 & $>.999$ \\
\hline Arrhythmia, atrial fibrillation & 16 & 16 & 22 & 22 & .367 \\
\hline Arrhythmia, ventricular & 1 & 1 & 2 & 2 & $>.999$ \\
\hline $\begin{array}{l}\text { Arrhythmia, permanent } \\
\text { pacemaker }\end{array}$ & 0 & 0 & 0 & 0 & \\
\hline \multicolumn{6}{|l|}{ Neurologic } \\
\hline Permanent stroke & 1 & 1 & 2 & 2 & $>.999$ \\
\hline Transient ischemic attack & 1 & 1 & 0 & 0 & .497 \\
\hline \multicolumn{6}{|l|}{ Renal } \\
\hline New failure* & 1 & 1 & 2 & 2 & $>.999$ \\
\hline New dialysis & 2 & 2 & 0 & 0 & .246 \\
\hline \multicolumn{6}{|l|}{ Pulmonary } \\
\hline $\begin{array}{l}\text { Pleural effusion, thoracocentesis } \\
\text { Infectiont }\end{array}$ & 9 & 9 & 17 & 17 & .096 \\
\hline Deep sternal & 2 & 2 & 1 & 1 & .621 \\
\hline Superficial sternal & 4 & 4 & 7 & 7 & .537 \\
\hline Conduit harvest site & 9 & 9 & 10 & 10 & $>.999$ \\
\hline \multicolumn{6}{|l|}{ Other } \\
\hline $\begin{array}{l}\text { Gastrointestinal } \\
\text { bleeding }\end{array}$ & 3 & 3 & 2 & 2 & .682 \\
\hline
\end{tabular}

*New renal failure was considered in the presence of creatinine greater than $2.0 \mathrm{mg} / \mathrm{dL}$ or $50 \%$ increase in creatinine with respect to baseline. tDeep sternal infection required major surgical débridement or muscle flap closure and antibiotic treatment; superficial sternal infection required antibiotics with or without minor irrigation and débridement only; conduit harvest site infection required antibiotics with or without irrigation and débridement only.

both groups $(41.3 \%$ for OPCAB vs $40.8 \%$ for CABG with $\mathrm{CPB}$, difference not statistically significant). Complete graft patency data will be presented after completion of serial cardiac catheterizations at 1-year follow-up.

Serum albumin was higher in the OPCAB group $(2.46 \pm$ $0.49 \mathrm{~g} / \mathrm{dL}$ vs $2.16 \pm 0.46 \mathrm{~g} / \mathrm{dL}, P<.001)$ in the early $(<2$ hours) postoperative period, suggesting less hemodilution in the OPCAB group. Postoperative thromboelastogram indices determined without heparinase were equivalent; indices measured with heparinase were significantly higher in the OPCAB group, indicating less residual coagulopathy after heparin neutralization. After adjustment for baseline values, postoperative thromboelastogram indices, fibrinogen levels, 
TABLE 4. Completeness of revascularization

\begin{tabular}{lccc}
\hline Variable & OPCAB $(\mathbf{n}=\mathbf{9 8})$ & CABG with CPB $(\mathbf{n}=\mathbf{9 9})$ & $\boldsymbol{P}$ value \\
\hline Grafts per patient & $3.39 \pm 1.04$ & $3.40 \pm 1.08$ & $.829^{*}$ \\
ICOR & $1.01 \pm 0.18$ & $1.00 \pm 0.09$ & $.219^{*}$ \\
ICOR lateral wall & $0.97 \pm 0.23$ & $0.98 \pm 0.10$ & $.857^{*}$ \\
Arterial grafts (\%) & $41.3 \%$ & $40.8 \%$ & .937 \\
\hline
\end{tabular}

${ }^{*}$ By Wilcoxon test.

international normalized ratios, and platelet levels all showed significantly less coagulopathy after OPCAB. Interestingly, cumulative chest tube output did not differ significantly between the groups at 4,8 , or 12 hours, although there was a trend toward more frequent thoracocentesis in the CABG with CPB group $(\mathrm{n}=17 / 99)$ than in the OPCAB group $(\mathrm{n}=9 / 98, P=.096)$. Patients in the OPCAB group received fewer units of blood, were more likely to avoid transfusion altogether, and had higher hematocrit at discharge (differences between groups were determined after adjustment for baseline levels by analysis of covariance; Table 5). This difference in transfusion requirement was most pronounced on the day of surgery. CPB was an independent predictor of transfusion (odds ratio 2.42, $P=$ .0073) according to multivariate analysis. Incidences of reoperation for bleeding were similar $(n=2 / 99$ for CABG with $\mathrm{CPB}$ vs $\mathrm{n}=1 / 98$ for $\mathrm{OPCAB}$ ).

Mean serum levels of creatine kinase MB and troponin I were significantly lower in the OPCAB group at 8, 16, 24, and 48 hours after the operation, suggesting less myocardial injury (Figure 1). Only 1 patient in the OPCAB group and 2 in the CABG with $\mathrm{CPB}$ group had new $\mathrm{Q}$ waves by Minnesota Code criteria, as determined at an independent, external core laboratory (Table 6). No patient in either group had both new $\mathrm{Q}$ waves and myocardial enzyme release in excess of 5 times the upper limit of normal. Five patients in the CABG with CPB group had new right bundle branch block on postoperative ECG, as opposed to none in the OPCAB group, a difference that approached statistical significance. There were no other significant differences in serial ECGs between the groups.

More patients in the OPCAB group met extubation criteria in the operating room $(\mathrm{n}=45 / 98$ for OPCAB vs $\mathrm{n}=$ $32 / 99$ for CABG with $\mathrm{CPB}, P=.057$ ) and within 4 hours after the operation $(\mathrm{n}=73 / 95$ for OPCAB vs $\mathrm{n}=50 / 95$ CABG with $\mathrm{CPB}, P=.001$ ). All patients in the OPCAB group were extubated within 24 hours after the operation, whereas 5 patients in the CABG with CPB group did not meet extubation criteria until more than 24 hours after the operation $(P=.059)$. Two patients in each group were reintubated for cardiopulmonary indications during the initial hospitalization. With all patient management governed by uniform, unbiased protocols, postoperative length of stay was significantly shorter after OPCAB (5.1 \pm 6.5 days $)$ than after CABG with CPB $(6.1 \pm 8.2$ days, $P=.005$ by Wilcoxon test). Interestingly, most of this difference was in length of stay after transfer from the intensive care unit (Table 7). Importantly, only 1 patient in each group required discharge to a short-term rehabilitation facility; all others were discharged to home.

\section{Thirty-day Follow-up}

Despite earlier discharge from hospital, patients in the OP$\mathrm{CAB}$ group were no more likely to be readmitted than were those in the $\mathrm{CABG}$ with $\mathrm{CPB}$ group. Five patients in the OPCAB group and 6 patients in the $\mathrm{CABG}$ with $\mathrm{CPB}$ group were readmitted to any hospital for any reason within 30 days after the operation. The causes of readmission are listed in Table 8. One patient in the CABG with CPB group had early graft failure, recurrent angina, and a myocardial infarction with ventricular fibrillation that necessitated emergency angioplasty and stent placement within 30 days after the operation. No other patient in either group had recurrent angina. None underwent repeated surgical revascularization.

\section{Discussion}

Previous nonrandomized comparisons of OPCAB and CABG with CPB applying sophisticated statistical methods to large databases ${ }^{8,9}$ have reported significant reductions in risk-adjusted mortality, stroke, acute renal failure, prolonged ventilator dependence, reexploration for bleeding, and other complications with OPCAB. However, legitimate criticism of these conclusions has centered on the nonrandomized nature of the studies and the inherent bias of patient selection for OPCAB. Although statistical methods of risk adjustment and modeling have been applied in earnest, they are imperfect techniques. It is important to note that in Cleveland and coworkers' rigorous analysis of the Society of Thoracic Surgeons database, ${ }^{8}$ the CABG with CPB group had greater proportions of patients with threevessel disease and of urgent and emergency cases than did the OPCAB group, illustrating the role of patient selection in determining the composition of these groups.

Randomized comparisons of OPCAB and CABG with $\mathrm{CPB}$ are therefore necessary to obviate these concerns. However, even the larger randomized studies to date, ${ }^{12,17}$ including this report, have limited statistical power to detect 

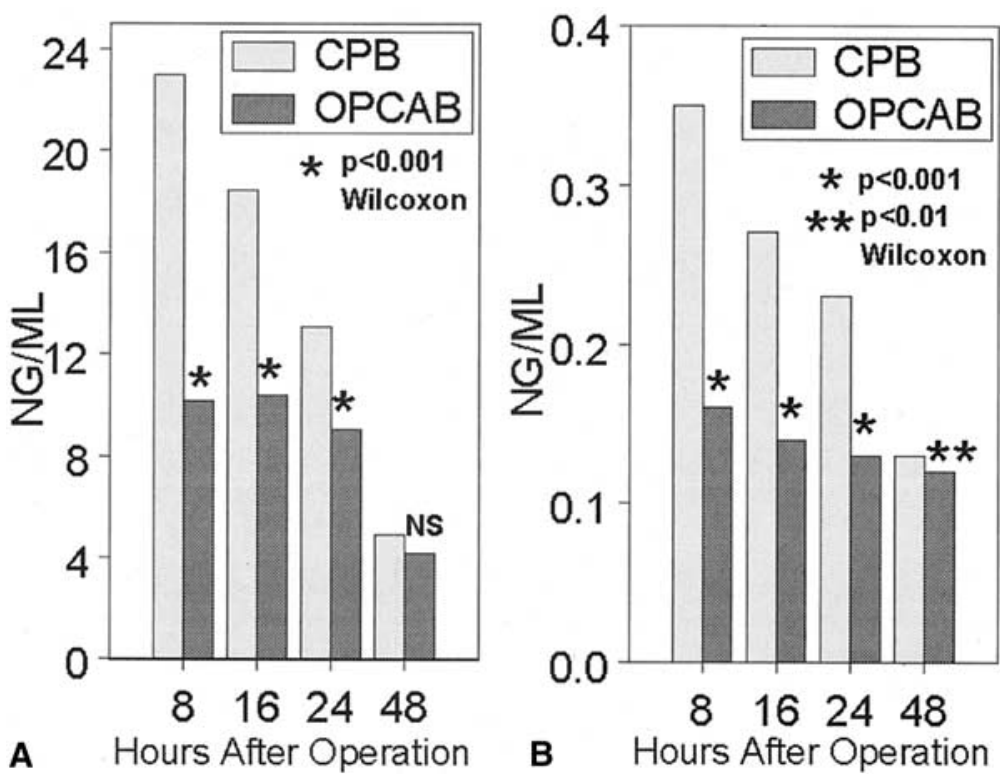

Figure 1. Serial postoperative measures of myocardial enzyme release were significantly lower in OPCAB (dark bars), than in CABG with CPB (light bars), suggesting less myocardial injury. A, Creatine kinase MB; B, troponin I.

TABLE 5. Coagulopathy and transfusion

\begin{tabular}{|c|c|c|c|}
\hline Variable & OPCAB & CABG with CPB & $P$ value \\
\hline \multicolumn{4}{|l|}{ Thromboelastogram index } \\
\hline Chest closed, without heparinase & $0.34 \pm 8.82(n=87)$ & $0.29 \pm 2.63(\mathrm{n}=76)$ & .850 \\
\hline Chest closed, with heparinase & $3.01 \pm 1.81(n=83)$ & $0.62 \pm 3.5(n=75)$ & $<.001^{*}$ \\
\hline International normalized ratio, early postoperative & $1.23 \pm 0.18(n=97)$ & $1.35 \pm 0.19(n=99)$ & $<.001 *$ \\
\hline Fibrinogen $(\mathrm{mg} / \mathrm{dL})$, early postoperative & $410.5 \pm 110.9(\mathrm{n}=89)$ & $331.8 \pm 87.35(\mathrm{n}=98)$ & $<.001^{*}$ \\
\hline Platelets $\left(10^{3} \mathrm{cells} / \mu \mathrm{L}\right)$, early, postoperative & $194.2 \pm 57.3(n=94)$ & $136.7 \pm 42.5(\mathrm{n}=99)$ & $<.001^{*}$ \\
\hline \multicolumn{4}{|l|}{ Hematocrit $(\%)$} \\
\hline $\begin{array}{l}\text { Postoperative d } 3 \\
\text { Discharge }\end{array}$ & $29.3 \pm 4.16(n=88)$ & $28.2 \pm 3.23(n=98)$ & $<.05^{*}$ \\
\hline Discharge & $30.6 \pm 3.74(n=98)$ & $29.5 \pm 3.30(n=99)$ & $<.05^{*}$ \\
\hline $\begin{array}{l}\text { Cumulative packed red blood cells (U/pt), surgery to } \\
\text { postoperative } d 3\end{array}$ & $0.40 \pm 0.77(n=98)$ & $0.61 \pm 1.79(\mathrm{n}=99)$ & .013 \\
\hline $\begin{array}{l}\text { Patients receiving any packed red blood cells (No.), } \\
\text { surgery to postoperative d } 3\end{array}$ & $25(26 \%)$ & $44(44 \%)$ & .007 \\
\hline
\end{tabular}

*Differences between groups after adjustment for baseline level (analysis of covariance).

differences between groups in end points that occur infrequently. No difference was found in mortality, stroke, perioperative myocardial infarction, or acute renal failure in either this study or previous randomized studies.

This study was designed to evaluate the crucial end points of completeness of revascularization and graft patency. Although 1-year graft patency data will not be available until after August 2002, results presented here demonstrate comparable completeness of revascularization in the two treatment groups, despite the fact that there was no exclusion of patients from this study on the basis of coronary anatomy, left ventricular function, or other comorbidities. All patients referred for elective, primary, isolated
CABG were considered eligible. The documentation of the intended revascularization before random assignment of patients minimized bias in the evaluation of completeness of revascularization performed. Although many authors have reported difficulty grafting the lateral wall of the left ventricle without CPB in their early experience, ${ }^{12,16}$ this study was undertaken after the operating surgeon had accumulated a personal experience in excess of 350 OPCAB cases. Thus the achievement of complete revascularization of the lateral wall in unselected patients by an experienced OP$\mathrm{CAB}$ surgeon has been demonstrated. Although it would be inappropriate to generalize these results to surgeons early in their experience with $\mathrm{OPCAB}$, it is reasonable to believe 
TABLE 6. New ECG abnormalities from baseline to intensive care unit

\begin{tabular}{lccr}
\hline Characteristic & $\begin{array}{c}\text { OPCAB } \\
\text { (n= 93) }\end{array}$ & $\begin{array}{c}\text { CABG with CPB } \\
\text { (n = 93) }\end{array}$ & $\boldsymbol{P}$ value \\
\hline $\begin{array}{l}\text { New 0-wave myocardial } \\
\text { infarction }\end{array}$ & 1 & 2 & $>.999$ \\
$\begin{array}{l}\text { New right bundle branch } \\
\text { block }\end{array}$ & 0 & 5 & .059 \\
$\begin{array}{l}\text { New primary atrioventricular } \\
\text { block (pulse rate }>120\end{array}$ & 0 & 2 & .497 \\
$\quad \begin{array}{l}\text { beats/min) } \\
\text { New left bundle branch } \\
\text { block* }\end{array}$ & 0 & 0 & $>.999$ \\
$\begin{array}{l}\text { Other new intraventricular } \\
\text { conduction defect }\end{array}$ & 1 & 1 & $>.999$ \\
$\begin{array}{l}\text { New atrial fibrillation or } \\
\text { atrial flutter }\end{array}$ & 0 & 2 & .497 \\
\hline
\end{tabular}

that similarly complete revascularization would be achieved by other surgeons who have developed extensive experience with OPCAB techniques. Thus broad application of OP$\mathrm{CAB}$ techniques to patients with multivessel disease need not lead to incomplete revascularization, with its documented negative consequences. ${ }^{17}$

Previous publications have documented the strong association between serum evidence of myocardial necrosis and future adverse cardiac events in patients undergoing percutaneous interventions ${ }^{18}$ and $\mathrm{CABG}$ with CPB. ${ }^{19}$ Although it is possible that some of the myocardial enzyme release in the $\mathrm{CPB}$ group was caused by cannulation of the right atrium, it is likely that the large majority derived from ventricular myocardium. Thus the finding that serum levels of myocardial enzymes were lower in the OPCAB group than in the CABG with $\mathrm{CPB}$ group at all time points measured is of particular interest. This result is consistent with those of previous randomized ${ }^{12,20}$ and nonrandomized $^{21}$ comparisons. Planned longitudinal follow-up of these two randomized groups of patients will allow documentation of longer-term outcomes correlated with perioperative elevation in serum levels of myocardial enzymes.

Among the various reported benefits of OPCAB relative to $\mathrm{CABG}$ with $\mathrm{CPB}$, reduction in transfusion requirement has been remarkably consistent across multiple stud-

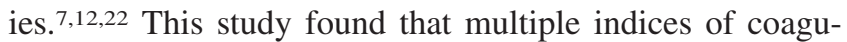
lopathy were significantly less deranged in OPCAB than in CABG with $\mathrm{CPB}$ and that patients undergoing OPCAB received fewer units of blood, were more likely to avoid transfusion altogether, and had a higher hematocrit at the time of hospital discharge. Interestingly, cumulative chest tube output was not significantly different between groups during the first 12 hours, despite the demonstrated difference in coagulopathy and the fact that most of the difference in transfusion requirement was seen during the day of
TABLE 7. Resource use

\begin{tabular}{|c|c|c|c|}
\hline Variable & $\begin{array}{c}\text { OPCAB } \\
(n=98)\end{array}$ & $\begin{array}{c}\text { CABG with CPB } \\
(\mathbf{n}=99)\end{array}$ & $P$ value \\
\hline \multicolumn{4}{|l|}{ Length of stay } \\
\hline $\begin{array}{l}\text { Surgery to discharge (d, } \\
\text { mean } \pm S D)\end{array}$ & $5.1 \pm 6.5$ & $6.1 \pm 8.1$ & .005 \\
\hline $\begin{array}{l}\text { Intensive care unit (d, } \\
\text { mean } \pm S D \text { ) }\end{array}$ & $23.9 \pm 14.5$ & $26.8 \pm 24.9$ & .820 \\
\hline $\begin{array}{l}\text { Readmitted to intensive } \\
\text { care unit (No.) }\end{array}$ & $5(5 \%)$ & $3(3 \%)$ & .500 \\
\hline \multicolumn{4}{|l|}{ Ventilation } \\
\hline $\begin{array}{l}\text { Extubated in operating } \\
\text { room (No.) }\end{array}$ & $45(46 \%)$ & $32(32 \%)$ & .057 \\
\hline Extubated $\leq 4 \mathrm{~h}$ (No.) & $73(77 \%)$ & $50(53 \%)$ & .001 \\
\hline Extubated $>24$ h (No.) & $0(0 \%)$ & $5(5 \%)$ & .059 \\
\hline $\begin{array}{l}\text { Reintubated during } \\
\text { hospitalization (No.) }\end{array}$ & $2(2 \%)$ & $2(2 \%)$ & $>.999$ \\
\hline $\begin{array}{l}\text { Skin to skin time (h, mean } \\
\quad \pm S D)\end{array}$ & $3.40 \pm 0.97$ & $3.41 \pm 0.81$ & .626 \\
\hline $\begin{array}{l}\text { Operating room time (h, } \\
\text { mean/SD) }\end{array}$ & $4.77 \pm 0.98$ & $4.69 \pm 0.85$ & .407 \\
\hline
\end{tabular}

TABLE 8. Complications requiring readmission within $\mathbf{3 0}$ days

\begin{tabular}{|c|c|c|c|c|}
\hline \multirow[b]{2}{*}{ Complication } & \multicolumn{2}{|c|}{$\begin{array}{l}\text { OPCAB } \\
(n=5)\end{array}$} & \multicolumn{2}{|c|}{$\begin{array}{c}\text { CABG with } \\
\text { CPB } \\
(n=6)\end{array}$} \\
\hline & No. & $\%$ & No. & $\%$ \\
\hline Atrial fibrillation & 0 & 0 & 3 & 3 \\
\hline Ventricular fibrillation & 0 & 0 & 1 & 1 \\
\hline Stent placement & 0 & 0 & 1 & 1 \\
\hline Angina & 0 & 0 & 1 & 1 \\
\hline Atypical chest pain & 1 & 1 & 0 & 0 \\
\hline Gastrointestinal bleeding & 0 & 0 & 1 & 1 \\
\hline Pleural effusions, thoracocentesis & 1 & 1 & 0 & 0 \\
\hline Subcutaneous emphysema & 1 & 1 & 0 & 0 \\
\hline Thrombectomy, catheter extremity & 0 & 0 & 1 & 1 \\
\hline Deep sternal wound infection & 0 & 0 & 1 & 1 \\
\hline Superficial sternal infection & 0 & 0 & 1 & 1 \\
\hline Harvest site infection & 2 & 2 & 0 & 0 \\
\hline
\end{tabular}

All differences not significant.

surgery. Thus it seems likely that the cardiopulmonary circuit itself either consumes or damages red blood cells to some degree, causing removal of these cells by the reticuloendothelial system in the first hours after surgery. A cell saver device was used in every case, to equalize efforts between groups to preserve red cell mass.

As economic considerations influence medical decision making to an increasing degree worldwide, the lengths of stay associated with alternative methods of surgical coronary revascularization are increasingly relevant. Consistent with previous randomized comparisons of selected patients, ${ }^{12,17}$ this study of unselected patients with multivessel 
disease demonstrated that OPCAB shortened postoperative length of stay by 1 full day. With all other outcome measures either equivalent or superior for the OPCAB group, the decrease in length of stay may prove to be an important influence on third-party payers and institutional administrators.

\section{Conclusion}

Relative to $\mathrm{CABG}$ with $\mathrm{CPB}$ in this prospective, randomized study of 200 unselected patients undergoing elective primary CABG, OPCAB achieved comparable completeness of revascularization and similar in-hospital and 30-day outcomes, shorter length of stay, reduced coagulopathy and transfusion requirement, and less myocardial injury.

We are indebted to the following referring physicians, without whose cooperation and collaboration the SMART Study would not have been possible: Dr Chituru Adele, Dr Homayoun Amin, Dr Michael Balk, Dr James Barnhill, Dr Michael Biddle, Dr Michael Cecil, Dr Jack Chen, Dr Terrance Collins, Dr Niranjan Dave, Dr James Day, Dr Jacinto Del Mazo, Dr Rajendra Desai, Dr Barry Dix, Dr Patrick Egbe, Dr Enrique Flores, Dr Ronald Freireich, Dr Randall Grimes, Dr Mark Hanson, Dr John Harsch, Dr David Hitson, Dr Bailey Johnson, Dr David Johnson, Dr George Jones, Dr Isaac Joseph, Dr Anna Kalynych, Dr Robert Kaufman, Dr Daniel Kleinman, Dr Devendra Koganti, Dr George Kramer, Dr David Lantz, Dr Mark Leimbach, Dr Henry Liberman, Dr John Madonna, Dr J. Jeffrey Marshall, Dr Walter Mashman, Dr K. M. Mathew, Dr Richard Matthews, Dr Julian McClendon, Dr John Merlino, Dr Krishna Mohan, Dr Subra Naidu, Dr Kamlish Nayak, Dr Narasimhulu Neelagaru, Dr Abiodun Olatidoye, Dr Arif Omar, Dr Donald Page, Dr Naresh Parikh, Dr Randolph Patterson, Dr Gopal Rao, Dr Bharati Reddy, Dr Kuchela Reddy, Dr Brian Remington, Dr Sheila Robinson, Dr Surender Sandella, Dr Tim Scully, Dr Methusamy Sekar, Dr Steven Sigman, Dr Gregory Simone, Dr Paul Simonoff, Dr Jeffrey Smith, Dr John Smith, Dr Prad Tummala, Dr James Van Buren, Dr Searle W. Videlefsky, Dr Byron Williams, and Dr Jimmie Williams.

\section{References}

1. Benetti FJ. Direct coronary surgery with saphenous vein bypass without either cardiopulmonary bypass or cardiac rest. J Cardiovasc Surg. 1985;26:217-22.

2. Buffolo E, de Andrade JC, Branco JN, Teles CA, Aguiar LF, Gomes WJ. Coronary artery bypass grafting without cardiopulmonary bypass. Ann Thorac Surg. 1996;61:63-6.

3. Puskas JD, Wright CE, Ronson RS, Brown WM, Gott JP, Guyton RA. Off-pump multivessel coronary bypass via sternotomy is safe and effective. Ann Thorac Surg. 1998;66:1068-72.

4. Hart JC, Spooner TH, Pym J, Flavin TF, Edgerton JR, Mack MJ, et al. A review of 1582 consecutive Octopus off-pump coronary bypass patients. Ann Thorac Surg. 2000;70:1017-20.

5. Bonchek LI, Ullyot DJ. Minimally invasive coronary bypass: a dissenting opinion. Circulation. 1998;98:495-7.

6. Cooley DA. Con: beating-heart surgery for coronary revascularization: is it the most important development since the introduction of the heart-lung machine? Ann Thorac Surg. 2000;70:1779-81.

7. Puskas JD, Thourani VH, Marshall JJ, Dempsey SJ, Steiner MA, Sammons BH, et al. Clinical outcomes, angiographic patency and resource utilization in 200 consecutive off-pump coronary bypass patients. Ann Thorac Surg. 2001;71:1477-84.

8. Cleveland JC, Shroyer AL, Chen AY, Peterson E, Grover FL. Offpump coronary artery bypass grafting decreases risk-adjusted mortality and morbidity. Ann Thorac Surg. 2001;72:1282-9.

9. Plomondon ME, Cleveland JC, Ludwig ST, Grunwald GK, Kiefe CI, Grover FL, et al. Off-pump coronary artery bypass is associated with improved risk-adjusted outcomes. Ann Thorac Surg. 2001;72:114-9.

10. Cartier R, Brann S, Dagennairs F, Martineau R, Couturier A. Systemic off-pump coronary artery revascularization in multivessel disease: an experience with 300 cases. J Thorac Cardiovasc Surg. 2000;199: 221-9.

11. Czerny M, Baumer H, Kilo J, Zuckermann A, Grubhofer G, Chevtchik $\mathrm{O}$, et al. Complete revascularization in coronary artery bypass grafting with and without cardiopulmonary bypass. Ann Thorac Surg. 2001; 71:165-9.

12. Van Dijk D, Nierich AP, Jansen EW, Nathoe HM, Suyker WJ, Diephuis JC, et al. Early outcome after off-pump versus on-pump coronary bypass surgery: results from a randomized study. Circulation. 2001;104:1761-6.

13. Ascione R, Lloyd CT, Underwood MJ, Lotto AA, Pitsis AA, Angelini GD. Economic outcome of off-pump coronary artery bypass surgery: a prospective randomized study. Ann Thorac Surg. 1999;68:2237-42.

14. Puskas JD, Vinten-Johansen J, Muraki S, Guyton RA. Myocardial protection for off-pump coronary artery bypass surgery. Semin Thorac Cardiovasc Surg. 2001;13:82-8.

15. Guyton RA, Thourani VH, Puskas JD, Shanewise JS, Steele MA, Palmer-Steele CL, et al. Perfusion-assisted direct coronary artery bypass: selective graft perfusion in off-pump cases. Ann Thorac Surg. 2000;69:171-5.

16. Angelini GD, Taylor FC, Reeves BC, Ascione R. Early and midterm outcome after off-pump and on-pump surgery in Beating Heart Against Cardioplegic Arrest Studies (BHACAS 1 and 2): a pooled analysis of two randomised controlled trials. Lancet. 2002;359:1194-9.

17. Jones EL, Weintraub WS. The importance of completeness of revascularization during long-term follow-up after coronary artery operations. J Thorac Cardiovasc Surg. 1996;112:227-37.

18. Califf RM, Abdelmeguid AE, Kuntz RE, Popma JJ, Davidson CJ, Cohen EA, et al. Myonecrosis after revascularization procedures. $J$ Am Coll Cardiol. 1998;31:241-51.

19. Costa MA, Carere RG, Lichtenstein SV, Foley DP, De Valk V, Lindenboom $\mathrm{W}$, et al. Incidence, predictors and significance of abnormal cardiac enzyme rise in patients treated with bypass surgery in the arterial revascularization therapies study (ARTS). Circulation. 2001;104:2689-93.

20. Ascione R, Lloyd CT, Gomes WJ, Caputo M, Bryan AJ, Angelini GD. Beating versus arrested heart revascularization: evaluation of myocardial function in a prospective randomized study. Eur J Cardiothorac Surg. 1999;15:685-90.

21. Kilger E, Pichler B, Weis F, Goetz A, Lamm P, Schutz A, et al. Markers of myocardial ischemia after minimally invasive and conventional coronary operation. Ann Thorac Surg. 2000;70:2023-8.

22. Ascione R, Williams S, Lloyd CT, Sundaramoorthi T, Pitsis AA, Angelini GD. Reduced postoperative blood loss and transfusion requirement after beating-heart coronary operations: a prospective randomized study. J Thorac Cardiovasc Surg. 2001;121:689-96.

\section{Discussion}

Dr Bruce W. Lytle (Cleveland, Ohio). First, I think that this is a pretty good study. These types of studies where you randomly assign a surgical procedure are not easy to do, and although it would always be nice to have more patients, it is difficult to get even 200 patients into a protocol like this. The random assignment was not consecutive, but in reading the randomization protocol it certainly seems reasonable. Although I do not completely understand all the statistics that were used to do it, that is just because I do not understand those kind of statistics. It seems to me that this is a fair random sample. Second, the differences in outcomes were 
very small. A lot of the difficulties in interpreting data concerning on-pump and off-pump surgery, even with nonrandom studies, has been that early outcomes do not appear to be much different.

My first question is, are the differences that you noted in enzyme elevation clinically important? It seems to me that those differences, although statistically significant, are not vast. Do you plan to establish the importance of those differences with longterm follow-up?

My second question is, when you talk about arterial grafts, there are a lot of different kinds of arterial grafts. My sense is that this is sort of a left internal thoracic artery to anterior descending and then radial to something else kind of study, which is a standard technique but not the same as complex internal thoracic artery grafting. Is that the case?

My third and final question is, you used the perfusion-assisted direct coronary artery bypass $(P A D C A B)$ type strategy, which I know that you have advocated in other work, for only 1 patient in this group to keep things standard, and with the good results of your standard off-pump technique, do you think that the other strategy is no longer necessary? What are your feelings about that?

Dr Puskas. Thank you, Dr Lytle. We have all benefited from your leadership in the field of CABG and your careful examination of outcomes. Your first question was in regard to the difference in enzyme release and whether that is a clinically important difference. The Q-wave infarct rate was not statistically different between groups. The enzyme release clearly was statistically different between groups. It may be that the prolonged length of stay, 1 more day, in that group had something to do with enzyme release or myocardial injury, or it may be that we need longer longitudinal follow-up of these groups to discover adverse cardiac events that may occur later. Certainly in the immediate in-hospital period, the difference in enzyme release was not correlated with dramatically different cardiac outcomes; the infarct rate was not significantly different, and the time spent in the intensive care unit was not significantly different. The difference in length of stay was after intensive care unit transfer for the most part. So we do intend to follow up these patients through time. We will be doing annual follow-ups for the foreseeable future and trying to correlate adverse cardiac events with preoperative and postoperative events and markers from the hospital stay.

Your second question related to arterial grafting. You are correct in assuming that with $41 \%$ of all grafts being arterial conduits, the left internal thoracic artery was essentially a uniform graft for all patients. Left radial artery grafting was also very common. We did, however, have several bilateral thoracic arteries, both in situ or as composite grafts, and in several cases composite grafts were taken off the internal thoracic pedicles and anastomosed to the lateral wall in either a surgical $\mathrm{Y}$ or sequential fashion to avoid manipulation of the ascending aorta. So there were a handful, or a couple of handfuls, of what you might consider complex arterial grafts with composite right off left internal thoracic artery anastomoses to multiple lateral wall vessels. As you know, that is not often an absolute necessity, and our standard grafting procedure was left internal thoracic artery to the left anterior descending coronary artery, left radial artery to the biggest lateral wall graft and veins to the right side.

Your third question related to PADCAB and our use of it. We did use the PADCAB for 1 procedure in the OPCAB group, a complex five-vessel CABG on a morbidly obese man with a profoundly depressed left ventricular ejection fraction and preoperative myocardial infarction. We considered the PADCAB to be helpful in keeping that man in stable condition during the operation. I think that it is also helpful during one's learning curve and for treating similar patients after one's learning curve. I think it does play a role. But this study was not directed to studying the benefit of PADCAB, so we tried to limit its application in this study to avoid confounding influences.

Dr Lawrence I. Bonchek (Lancaster, $\mathrm{Pa}$ ). Completion of such a randomized study is a considerable achievement, and I congratulate Puskas and coworkers. It is interesting that another randomized study by Jansen and coworkers from The Netherlands, recently published in Circulation, found that the only major benefits of OPCAB were less release of cardiac enzymes and shorter length of stay. Neither that study nor this revealed differences where we would have hoped to see them, in the incidences of neurologic deficits, atrial fibrillation, and renal or pulmonary complications.

First, can you discuss the significance of the difference in enzyme release? Because in your study OPCAB was done with clamping of single arteries and thus only brief regional ischemia, whereas $\mathrm{CABG}$ with $\mathrm{CPB}$ was done with prolonged global ischemia and cardioplegic cell membrane paralysis, the difference in enzyme release is understandable. Of course, $\mathrm{CABG}$ with $\mathrm{CPB}$ can also be done with single-vessel occlusion without cardioplegia, as is done by our group and many others, which might well eliminate any difference in enzyme release between the two techniques, except for the unavoidable release related to cannulation of the right atrium in on-pump cases. I therefore suspect that the differences in enzyme release are unimportant.

Second, it is important to note that these excellent results were achieved by an exceptional surgeon. This does not reassure me that OPCAB is for everyone. In fact, in large groups that do a lot of OPCAB procedures, most of the cases are done by a few surgeons. Would you also comment on that observation?

And finally, because you were kind enough to discuss this protocol with me before you began the study, I know that one of your objectives was to use blinding as much as possible; however, you did not discuss that in your presentation. Certainly if the caregivers who made the decision for hospital discharge were not blinded, that is a highly subjective decision.

Dr Puskas. Indeed, Larry and I did have several conversations about the proposed strategy for designing this study about 4 years ago, and he raises some of the same concerns today. Actually, I did mention in my earlier presentation that all management was according to written, unbiased, criteria-driven protocols and that all the nonoperative care providers, patients, their families, and referring cardiologists, as well as the nursing staff, were blinded to group assignment. The patients were identified only as study patients, and whether the procedure was OPCAB or CABG with $\mathrm{CPB}$ was not revealed unless it was essential for appropriate clinical management.

Your first question, Dr Bonchek, related to Jansen and colleagues' report from Utrecht of a randomized study where they selected patients not requiring lateral wall grafts and also noted a decrease in creatine kinase MB release and a shorter length of stay. That study enrolled, I believe, 281 patients; ours enrolled 200. As you well know, with the statistical power of those numbers, it is 
unlikely and indeed unexpected that we would be able to demonstrate statistically significant changes in outcomes that occur infrequently. Specifically, mortality, stroke, and similar infrequent events are not going to be demonstrated to be different until we have a multicenter, prospective, randomized trial enrolling at least 1000 patients. Our best evidence that OPCAB does reduce those events comes from Cleveland and others, who have carefully analyzed the Society of Thoracic Surgeons database of many tens of thousands of patients and demonstrated there is a benefit of OPCAB with respect to those end points.

Dr Bonchek, you also commented that the creatine kinase MB release is understandable and therefore unimportant. I am not sure that I would agree with that logical step. I do think that it is understandable. I do think that applying a crossclamp to the aorta and inducing global myocardial ischemia is responsible for the creatine kinase MB release. I am not sure that the application of a clamp and global ischemia is therefore unimportant. The clinical significance of it may become more apparent as we more carefully examine why length of stay is shorter for OPCAB and whether longitudinal follow-up reveals these patients to have a different set of cardiac outcomes.

Your final question related to the generalizability of these results among other surgeons. It is true that OPCAB has a long learning curve; it does require a certain devotion to the field and a certain persistence in developing one's own technique. I personally enjoy the operation. I know that there are others who do not. I do think that you will find that surgeons who choose to take up this operation and perfect their own skills will be able to achieve every bit as good results as I have demonstrated today.

Access to The Journal of Thoracic and Cardiovascular Surgery Online is reserved for print subscribers!

Full-text access to The Journal of Thoracic and Cardiovascular Surgery Online is available for all print subscribers. To activate your individual online subscription, please visit The Journal of Thoracic and Cardiovascular Surgery Online, point your browser to http://www.mosby.com/jtcvs, follow the prompts to activate your online access, and follow the instructions. To activate your account, you will need your subscriber account number, which you can find on your mailing label (note: the number of digits in your subscriber account number varies from 6 to 10). See the example below in which the subscriber account number has been circled:

\section{Sample mailing label}

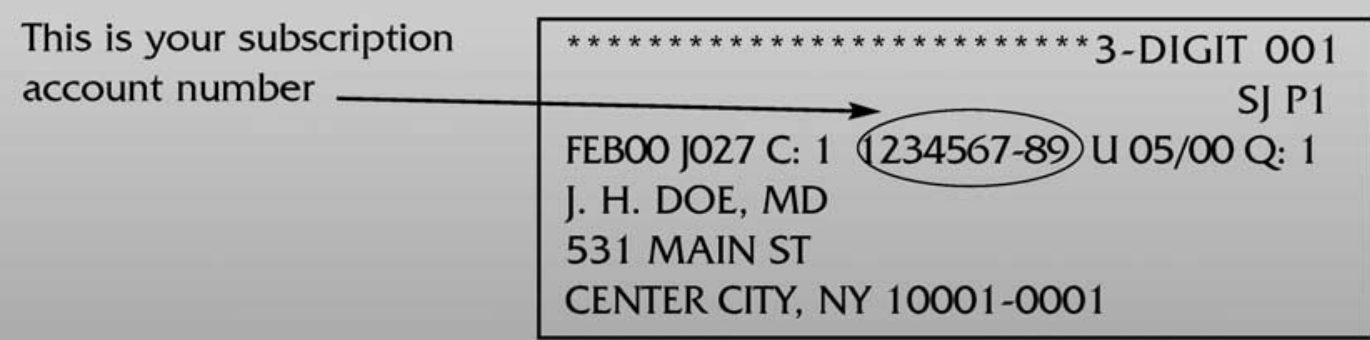

Personal subscriptions to The Journal of Thoracic and Cardiovascular Surgery Online are for individual use only and may not be transferred. Use of The Joumal of Thoracic and Cardiovascular Surgery Online is subject to agreement to the terms and conditions as indicated online. 